\title{
Counting on quality in endoscopy globally: all that matters now
}

\author{
Krish Ragunath \\ Nottingham Digestive Diseases Centre, NIHR Nottingham Digestive Diseases Biomedical Research Centre, University of Nottingham \& \\ Nottingham University Hospitals NHS Trust, Nottingham, UK \\ Correspondence to: Professor Krish Ragunath, MD, MPhil, FRCP, FASGE. Nottingham Digestive Disease Centre, E Floor, West Block, Queens \\ Medical Centre, Nottingham University Hospitals NHS Trust, Nottingham NG7 2UH, UK. Email: K.Ragunath@nottingham.ac.uk. \\ Response to: Chiu PW. Editorial on quality standards in upper gastrointestinal endoscopy: a position statement of the British Society of \\ Gastroenterology (BSG) and Association of Upper Gastrointestinal Surgeons of Great Britain and Ireland (AUGIS). Transl Gastroenterol Hepatol \\ 2018;3:13. \\ Cho YK. Quality standards and performance measures: steps to high quality diagnostic endoscopy. Transl Gastroenterol Hepatol $2018 ; 3: 7$.
}

Received: 04 December 2018; Accepted: 13 December 2018; Published: 21 December 2018.

doi: $10.21037 / \operatorname{tgh} .2018 .12 .06$

View this article at: http://dx.doi.org/10.21037/tgh.2018.12.06

I appreciate that Drs. Cho and Chiu agree regarding the importance of defining quality standards in upper gastrointestinal endoscopy $(1,2)$. However, a few points have been raised with regards to the position statement by the British Society of Gastroenterology (BSG) and the Association of Upper Gastrointestinal Surgeons of Great Britain and Ireland (AUGIS) (3). The number of esophago-gastro-duodenoscopy (EGD) procedures to be performed annually to maintain competency and highquality performance is a contentious issue. To clarify, the Joint Advisory Group (JAG) oversees the endoscopy training and accreditation in the UK (4). A trainee endoscopist should complete a minimum number of 200 EGD under supervision before he or she is assessed for competency via the Direct Observation of Procedural Skills (DOPS) summative assessment. It may well be that some of the endoscopy trainees may require well above the 200 minimum EGD to acquire the skills to achieve this level of proficiency for independent practice. Once the trainee endoscopist is assessed and deemed successful by two independent JAG approved assessors the EGD accreditation certificate is issued. As one can appreciate, a procedural skill such as endoscopy requires constant practice to perform the task to the standard required to obtain the accreditation. In the absence of continued practice there will be 'skill decay' that can be detrimental to patient care. This 'skill decay' is well known in surgical practice and military medicine (5). In the absence of critical evidence in endoscopic skills acquisition and decay, we need to look up to similar field like laparoscopic surgery that requires psychomotor and cognitive skills. The number of EGD (100 per annum) to be aimed for maintaining competency is arbitrary which is $50 \%$ of the minimum number required to train in EGD. This may be an overcall; however, the intention was to prevent the occasional endoscopist doing a few EGDs now and then. Cho mentions that the Korean Society of Gastrointestinal Endoscopy (KSGE) supports continuous medical education instead of annual volume to maintain competency. One can argue that endoscopy requires psychomotor and cognitive skills that cannot be provided by medical education alone. This will encourage 'arm chair' endoscopist that will be detrimental to our patients whilst protecting individual endoscopist interest. Quantity is what we count, but ultimately quality is what we count on.

Optical diagnosis is a growing field with modern advanced imaging technology. However, biopsy and pathological examination is the ultimate gold standard to confirm an endoscopic diagnosis. Chiu comments about the number of biopsies taken for a malignant looking lesion. The proposed six biopsies can cause fibrosis and can hinder safe endoscopic resection of the neoplasm. I agree that several biopsies from an early neoplasia that has the potential for endoscopic resection can impede effective endoscopic therapy. However, the statement is clear to take six biopsies in a malignant looking lesion, which means a locally advanced lesion not amenable to endoscopic therapy. It is important to have adequate tissue for diagnosis and personalised medicine and individualised therapy. Perhaps this was misinterpreted by Chiu and I would like to clarify this statement.

In conclusion, I am glad that the editorials have been 
supportive of a global approach to high quality upper GI endoscopy for early cancer diagnosis that will greatly improve patient outcome.

\section{Acknowledgements}

None.

\section{Footnote}

Conflicts of Interest: The author has no conflicts of interest to declare.

\section{References}

1. Cho YK. Quality standards and performance measures:

doi: $10.21037 / \operatorname{tgh} .2018 .12 .06$

Cite this article as: Ragunath $\mathrm{K}$. Counting on quality in endoscopy globally: all that matters now. Transl Gastroenterol Hepatol 2018;3:105. steps to high quality diagnostic endoscopy. Transl Gastroenterol Hepatol 2018;3:7.

2. Chiu PW. Editorial on quality standards in upper gastrointestinal endoscopy: a position statement of the British Society of Gastroenterology (BSG) and Association of Upper Gastrointestinal Surgeons of Great Britain and Ireland (AUGIS). Transl Gastroenterol Hepatol 2018;3:13.

3. Beg S, Ragunath K, Wyman A et al. Quality standards in upper gastrointestinal endoscopy: a position statement of the British Society of Gastroenterology (BSG) and Association of Upper Gastrointestinal Surgeons of Great Britain and Ireland (AUGIS). Gut 2017;66:1886-99.

4. Joint advisory group on GI Endoscopy. Available online: http://www.thejag.org.uk

5. Perez RS. Skinner A, Weyhrauch P, et al. Prevention of surgical skill decay. Mil Med 2013;178:76-86. 